\title{
The Science of Human Interaction
}

\author{
Shyam Mehta*
}

\begin{abstract}
In the case of a man and woman, there are four forces that drive them together. These four are weak, semi strong, strong or super strong, depending on distance. Distance here is not centimetres or kilometres, but is measured in terms of love and affection. Affection can be negative, which means that you dislike somebody, it can be zero which means that you are indifferent to him or her (for example, you might not know him or her), it can be modest and it can be large. When your affection for your spouse exceeds your affection for yourself, it turns into love. So, this is the measure of distance between a man and a woman.
\end{abstract}

KEY WORDS- Psychology, the mind, love, self-interest, greed

\section{TEXT}

The force that drives two people together when the distance is negative is called greed. It is in yoga philosophy known as breaking the fifth of the principles of ethics, aparigraha (non acceptance of gifts). You should not believe that just because a man and a woman live together as man and wife they have positive affection for each other. In a typical marriage after about four years, affection has turned negative. Because the mind is involved, neither the man nor the woman knows the true status of their heart. Hence, they will not know whether they have positive or negative affection for their partner. This is all to do with Western education: focusing on mental activity. Obviously, the greater is their dislike of each other, the greater is their greed, if they are together. Just as an appropriately designed test can measure the dislike that you have of another person, one can also determine greediness. You will find that there is a 1 to 1 correspondence.

*Student, University of Cambridge, London, United Kingdom 
As dislike turns to like and the distance between the two people becomes small, greediness (between them) becomes small also. It disappears completely only when your love for your partner becomes infinitely more than your love for yourself. This then is the first law of human interaction.

Now let us turn to the second law of human interaction. Again, classification into weak or strong etc. cannot be made, just as it cannot be made for the four physical forces. The classification is best made based on distance. So, since we have started with a classification of forces which are strong when the distance is large, let us move to the next force which is strongest, which is dominant, when the distance is about zero. At this distance, you are indifferent to your partner or acquaintance. There is a business relationship. The relationship is about trade. In other words, it is about self-interest. The second law of human interaction is to do with self-interest. Every human being when they meet someone to whom they are indifferent operates on the basis of selfinterest. There may be other forces as well, but this is the second force underlying human interactions. Self-interest drives the deal, drives what happens whenever the two people interact more than any other of the four forces. As the distance becomes further (dislike) or closer (affection and love) self-interest becomes less of a driving motive.

The third law of human interaction takes over when the distance is getting small. In other words, it reaches a maximum when affection for your partner is at the point of becoming love. You are close to each other. At least, you are close to him or her. At this distance, the driving motive behind your interaction with him or her is sex. Nowadays, very few people have large affection for their partners. Hence, they are preoccupied with their business and work affairs, with quarreling and so forth. Sex is low down on their priorities. When you reach the point, or rather if you ever reached the point where you love your spouse as much as you love yourself, then your desire for him or her is enormous. You can reach just thinking or looking at him or her. You need him or her amazingly. One should not think that sex desire is small at other distances. Sex is the most basic human and animal driving force. An animal does not have greed. It has self-interest and sex. Sexual desire in an animal happens even though it does not love, cannot love.

Similarly, with a human, sexual desire becomes enormously strong as the distance to orgasm 
approaches.

These are the two factors that govern the strength of sexual desire for human beings. However, nowadays sexual desire is becoming weaker and weaker even when these two measures of distance are fixed. If these two measures of distance are large then sexual desire is small. Let us now turn to the final driving force behind all human interaction. This is the wish to help other people. As your affection or your love increases for a person, your desire to help him or her increases. In the case of God, there are those who wish to come close to Him. His love for such a person is infinite. His desire to help that person is correspondingly infinite. It cannot be measured. In the case of a human, it can be measured. It never reaches infinity. A man may say or a woman may say I love you with all of my heart. But this does not mean that they have infinitely more love for you than they have for themselves. The following diagram illustrates the above four fundamental motives:

I have a scale in the work that I do that measures, approximately, the love or affection or dislike that you have for another person. At the point where affection turns into love, my "love

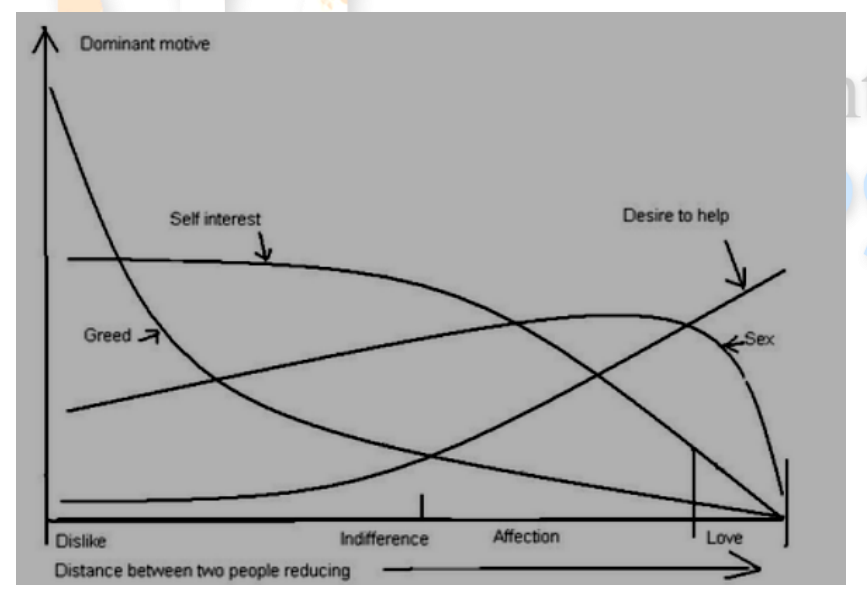
percentage" is 40 percent. Infinite love is on this scale 100 percent. It cannot exceed 100 percent. So, when my love percentage is less than zero percent, greed increasingly is the force that keeps a couple together.

When the love percentage is about zero percent, they are together because of selfinterest. In the zone of the love percentage being between zero percent and 40 percent, the three main factors that operate are self-interest, sex and a wish to help the partner. When the percentage reaches 40 percent, self-interest is only a small factor. The dominant factor is either sex or the desire to help your partner.

When the percentage reaches about 95 percent, you surrender your, body mind and soul to your partner. In India, this is called Ishvara Pranidhana: surrender to God. At this stage, sex is nice.

But by far and away the dominant factor is desire to help your partner. It is not possible for a 
The International Journal of Indian Psychology: Volume: 01 | Issue: 04 No. 2 | ISSN 2348-5396

human being to exceed this 95 percent love percentage.

Just to sum up the concept of human distance, there is a single scale, ranging from nearly complete dislike $(-95 \%)$ to indifference $(0 \%)$ to affection, leading to love (40\% to $95 \%$ ).

Some people never seem to take notice of what one says, even though it is in their benefit. There are 3 types of people, those who listen, those who read and those who do neither. When two people interact, it is their distance apart (see above) that determines whether they will accept what you say or accept what you write to them. If the dominant motive is greed, they will do neither. If the dominant motive is the desire to help, they will also do neither. If the dominant motive is sex, the person will accept what you write to them and if it is self-interest, they will accept what you say. So, it is quite easy to find out how to approach the person, or whether there is no point.

This is the complete science of human interaction.

\section{CONCLUSION}

There are four motives which govern your interactions with other people: self-interest, greed, sex and desire to help. How powerful these motives are depending on your 'distance' from the other person, and this distance is measured in terms of affection. Affection can be negative, zero, small positive or large and positive.

\section{ABOUT THE AUTHOR}

Shyam Mehta, by exclusively trying to follow God's will, and by wishing to help all mankind develop love and happiness in their lives, gets constant inspiration from God. He has written hundreds of articles and over 50 books on a wide variety of subjects such as sex, love, marriage, the emotions, the mind, religion, yoga, health, history, how to educate children, economics, physics, investment, and philosophy. 